\title{
Impacts of Small-Scale Urban Encroachment on Air Temperature Observations
}

\author{
RONALD D. LEEPER \\ Cooperative Institute for Climate and Satellites, North Carolina State University, and NOAA/National Centers for \\ Environmental Information, Asheville, North Carolina \\ JOHN KOCHENDORFER \\ NOAA/Atmospheric Turbulent Diffusion Division, Oak Ridge, Tennessee
}

TIMOTHY A. HENDERSON

North Carolina State Climate Office, Raleigh, North Carolina

MichAEL A. PALECKI

NOAA/National Centers for Environmental Information, Asheville, North Carolina

(Manuscript received 7 January 2019, in final form 8 April 2019)

\begin{abstract}
A field experiment was performed in Oak Ridge, Tennessee, with four instrumented towers placed over grass at increasing distances $(4,30,50,124$, and $300 \mathrm{~m})$ from a built-up area. Stations were aligned in such a way to simulate the impact of small-scale encroachment on temperature observations. As expected, temperature observations were warmest for the site closest to the built environment with an average temperature difference of $0.31^{\circ}$ and $0.24^{\circ} \mathrm{C}$ for aspirated and unaspirated sensors, respectively. Mean aspirated temperature differences were greater during the evening $\left(0.47^{\circ} \mathrm{C}\right)$ than during the day $\left(0.16^{\circ} \mathrm{C}\right)$. This was particularly true for evenings following greater daytime solar insolation $\left(20+\mathrm{MJ} \mathrm{day}^{-1}\right)$ with surface winds from the direction of the built environment where mean differences exceeded $0.80^{\circ} \mathrm{C}$. The impact of the built environment on air temperature diminished with distance with a warm bias only detectable out to tower $\mathrm{B}^{\prime}$ located $50 \mathrm{~m}$ away. The experimental findings were comparable to a known case of urban encroachment at a U.S. Climate Reference Network station in Kingston, Rhode Island. The experimental and operational results both lead to reductions in the diurnal temperature range of $\sim 0.39^{\circ} \mathrm{C}$ for fan-aspirated sensors. Interestingly, the unaspirated sensor had a larger reduction in diurnal temperature range (DTR) of $0.48^{\circ} \mathrm{C}$. These results suggest that small-scale urban encroachment within $50 \mathrm{~m}$ of a station can have important impacts on daily temperature extrema (maximum and minimum) with the magnitude of these differences dependent upon prevailing environmental conditions and sensing technology.
\end{abstract}

\section{Introduction}

It is well understood that land cover influences nearsurface air temperature observations through the partitioning of the surface energy budget (Mahmood et al. 2014; Oke 1982). In built environments, artificial surfaces such as asphalt, buildings, and roofs alter energy fluxes in two ways. The first is a reduction of evapotranspiring surfaces (i.e., grasses and trees) that elevates sensible heating (Arnfield 2003; Oke 1982; Shem and Shepherd 2009; Grossman-Clarke et al. 2010) and

Corresponding author: Ronald D. Leeper, ronnieleeper@ cicsnc.org local air temperatures compared to rural environments. Second, urban surfaces have a greater capacity to store solar energy during the day than the land cover (grasses, trees, bare soil, etc.) of rural environments (Mahmood et al. 2014), which leads to differential cooling rates at night (Oke 1982). The later factor (differential rates of cooling) is thought to be the primary driver of the urban heat island (UHI) effect (Oke 1982). As a result, the UHI has been found to primarily impact minimum temperatures and dampen the diurnal temperature range (DTR), in addition to influencing turbulent mixing, convection, and precipitation over and downwind of urban areas (Mahmood et al. 2014). The UHI 
temperature signal has also been found to extend beyond the urban area in light wind conditions (Oke 1982).

Studies have found that the magnitude of the UHI signal can vary by the size of the urban area as well as environmental conditions. In this study, we were primarily interested in relatively small-scale (microscale) changes such as the construction of nearby roadways, parking lots, and single story buildings (which we refer to as encroachment hereafter) and their impact on station observations. Given our focus on smaller-scale encroachment, its effects on weather and climate networks can be difficult to detect and quantify. However, the identification of encroached stations is important to the climate monitoring community because long term in situ data from temporally stable locations (i.e., little to no surrounding land-cover change) with few data gaps and/ or station moves are preferred in regional and national climate assessments. Many studies focused on the impact of urbanization on long term temperature records (e.g., Gallo et al. 1999; Peterson 2003; Parker 2006) have shown that carefully selected networks produce accurate regional measurements of air temperature change over time. However, the availability of in situ stations meeting these requirements has decreased over time as rural and suburban areas continue to be developed (Streutker 2003).

The importance of encroachment and other factors is evidenced by the substantial efforts that have been made to address the temporal stability issue for climate monitoring, including improved quality control of air temperature records, homogenization of those records, and the development of high-quality reference networks such as the U.S. Climate Reference Network (USCRN). The pairwise homogenization algorithm and advanced quality control systems (Menne and Williams 2009; Menne et al. 2009, 2010; Williams et al. 2012) were developed in part to detect and account for UHI effects related to encroachment, station moves or the U.S. Cooperative Observer Program (COOP) network's modernization, which often resulted in slight relocations of a station toward buildings (Quayle et al. 1991). These efforts have largely succeeded at eliminating most of the urbanization signal from the U.S. Historical Climatology Network (USHCN) temperature dataset (Hausfather et al. 2013). While detection of urban signals for climate analysis is necessary, the effects of urbanization and encroachment on air temperature measurements are real and can have important biological and physiological effects on crop development (Battisti and Naylor 2009; Lobell 2007), ecosystem net carbon dioxide exchange (Yi et al. 2010), human health responses to heat (Bunker et al. 2016), and vector-borne diseases (Paaijmans et al. 2010).
The USCRN was designed to create a bias-free climate record for the United States, in addition to serving as a reference to quantify the impacts of station biases, including urbanization (Diamond et al. 2013; Leeper et al. 2015). To achieve this goal, the USCRN used criteria in the selection process that inversely awarded points to a location based upon its proximity to local bias sources (urban, water bodies, tree canopy, and other obstacles; Leroy 1998; NOAA 2002; WMO 2014). These points were then used to classify candidate sites and assess their sensitivity to local influences and representativeness of the surrounding area. For temperature, preference was given to sites located farther than $100 \mathrm{~m}$ from artificial heating sources or water bodies. The USCRN site selection process balanced the representativeness score with the anticipated temporal stability of the site (likelihood of future changes that may impact a site) and its accessibility in the selection process. After installation, each site was visited annually for maintenance and calibration and to photographically document changes in the vicinity of the station.

During one of these annual visits, site technicians noted encroachment at the Kingston, Rhode Island, Plains Road Site station. From discussions with the site host, there were plans to expand a parking lot, reroute a road, and move a heated greenhouse all within $100 \mathrm{~m}$ of the station. Rather than remove this station prior to construction, it was decided to leave the station in place and record the nature of the air temperature changes caused by the encroachment. This decision was feasible because of the existence of a second Kingston USCRN station (Peckham Farm Site) only $1.4 \mathrm{~km}$ to the south that assured continuity of the climate record at this location, and provided an unbiased observation set for comparisons.

While urban encroachment is thought to impact temperature measurements, there are few studies of small-scale encroachment on station observations that account for its impact by location (distance to human-built structures) and choice of sensing technology. The latter point is rather interesting given the technological advancements in observing instrumentation, including fan-aspirated shielding and improvements in sensor accuracy and response times (e.g., platinum resistance thermometers) that may affect measurement sensitivity to encroachment. Improved estimates of encroachment impact on station measurements from this field experiment can aid in identifying an encroachment signal at existing in situ stations. Given the influence of the UHI signal to biological and physiological responses and its negative impact on climate studies, an urbanization indicator for in situ datasets can be useful in a variety of applications. 


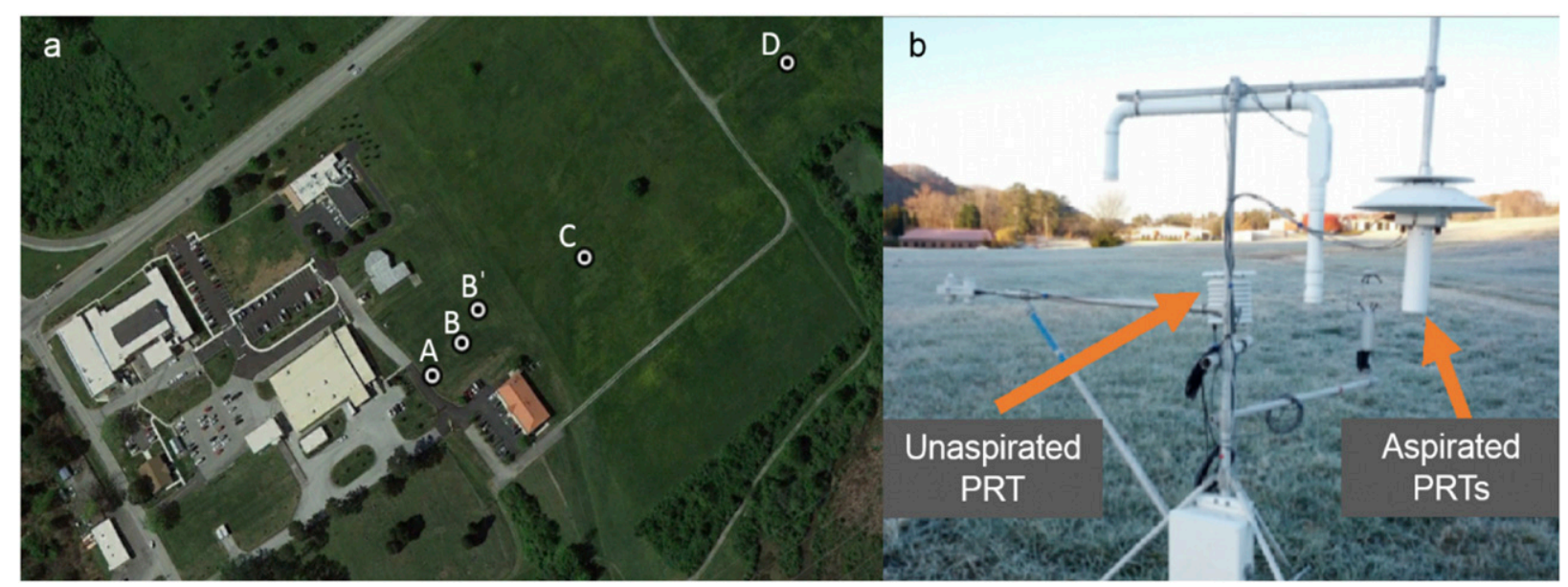

FIG. 1. (a) Placement of tower A through tower D at increasing distance from urban area; (b) a photo of tower D instrumentation showing the aspirated Met One shield that has three PRTs and the unaspirated multiple plate shield with a single PRT.

The purpose of this study was to evaluate the effects of small-scale urban encroachment by quantifying the impacts of a human-built environment (built structures with paved parking areas) on air temperature measurements. Observation stations were placed at five distances $(4,30,50,124$, and $309 \mathrm{~m}$ away) from a built environment to replicate different degrees of exposure to encroachment on station measurements. Subhourly temperatures at each site were monitored using both naturally and mechanically aspirated shields to evaluate aspiration effects on temperature responses to the built environment. In addition to temperature, these stations were equipped to monitor solar radiation, wind speed, and wind direction to determine how the urban signal varied with atmospheric conditions. These results were then compared to the USCRN station that underwent urban encroachment. This analysis can be used to help quantify the effects of urban encroachment on air temperature measured under differing aspiration and environmental conditions.

\section{Field experiment}

To explore the impact of urban encroachment on air temperature, four instrumented towers were deployed at varying distances from a cluster of buildings and paved surfaces (Fig. 1a) for an 18-month period between 1 November 2012 and 24 April 2014. The towers (A, B, $\mathrm{C}$, and $\mathrm{D}$ ) were placed downwind (from southwest to northeast) of the small urbanized area at distances of 4 , 30,124 , and $309 \mathrm{~m}$, respectively. Tower B was moved to a new location (tower $\mathrm{B}^{\prime}$ ) $50 \mathrm{~m}$ from the urban area halfway through the study period on 30 July 2013 . This is a more complex situation than previous studies that have looked at the impacts of a single road on surrounding conditions (Kumamoto et al. 2013).

All towers were instrumented with three Thermometrics $1000 \Omega$ platinum resistance thermometers (PRTs) placed within a Met One Instruments (Model 076B) fan-aspirated radiation shield (Fig. 1b). The PRTs were logged on Campbell Scientific CR3000 loggers using a 4-wire bridge and current excitation. Towers were additionally instrumented with $1.5-\mathrm{m}$ wind speed and direction, global solar radiation, and incoming and outgoing longwave radiation sensors. A single PRT was placed within a naturally aspirated multiple plate radiation shield (Fig. 1b) at towers A, $\mathrm{C}$, and D. The multiple plate radiation or "beehive" shield was the same as used by the National Weather Service (NWS) for COOP sites with maximum-minimum temperature sensors (MMTS).

It is well known that temperature observations from unaspirated sensors tend to have greater radiation biases that result in cooler evenings and warmer daytime observations when compared to aspirated sensors in similar settings (Leeper et al. 2015). The use of both fan and naturally aspirated shielding types (referred to as "aspirated" and "unaspirated," respectively) allowed the impact of urban encroachment on air temperature measurements to be explored by the separate types of shield aspiration found in national networks across the United States. Prior to the beginning of the field experiment, the instrumented towers were collocated near location D as depicted in Fig. 1a. During this period, the instruments for all stations were subject to a field intercomparison study. Temperatures were related separately to tower D's aspirated and unaspirated sensors using a linear regression to account for any subtle offsets that can arise from the instrument configuration in the 
field. Prior to this, the PRTs were calibrated in an oilfilled calibration bath (Hart Scientific Model 7380) against National Institute of Standards and Technology (NIST)-traceable standards. The total uncertainty of the bath calibration was $0.03^{\circ} \mathrm{C}$, and the uncertainty in the field intercomparison was $0.07^{\circ}$ and $0.08^{\circ} \mathrm{C}$ for aspirated and unaspirated sensors, respectively.

\section{Methodology}

\section{a. Tower comparisons}

Air temperature biases were analyzed by comparing temperature observations at all towers to tower D. In these comparisons, only temperature observations made using the same sensing and shielding technologies were compared among the towers with tower $\mathrm{D}$ serving as a control. Air temperature measurements were averaged over a moving 5-min window applied to the 16-s-resolution data. The 5-min moving average provided some measurement stability over the raw 16 -s data by mitigating the impact of high-frequency, turbulent-scale changes in air temperature between aspirated and unaspirated sensors.

The experimental analysis was performed in two parts. An initial comparison focused on the magnitude of the air temperature differences between tower A and tower D for both aspirated and unaspirated observations under a variety of atmospheric conditions. The effects of wind speed and direction (measured at tower A), incoming solar radiation (measured at tower D), and seasonal air temperature biases were evaluated to determine environmental conditions that enhanced or diminished the urban signal. Second, temperature differences with tower $\mathrm{D}$ were compared across all towers $(\mathrm{A}-\mathrm{C})$ to evaluate the relationship between the urban signal and distance.

A series of quality control checks were applied to the 16-s tower observations. The first check applied was to ensure battery voltages were not below $11.2 \mathrm{~V}$, which was associated with unreliable measurements from some of the sensors. All observations at a tower when battery voltages dipped below $11.2 \mathrm{~V}$ were set to missing. Second, a pairwise comparison similar to the quality control (QC) method applied to USCRN station observations (Leeper et al. 2015) was performed with the three aspirated PRTs collocated in the Met One shield. This pairwise method compared each of the three sensors to the others: PRT1-PRT2, PRT1PRT3, and PRT2-PRT3. A PRT differing from the other PRTs by $1.0^{\circ} \mathrm{C}$ or more was set to missing. The PRTs within the Met One shield that passed the QC checks were then averaged to produce a single $16 \mathrm{~s}$ fan-aspirated temperature observation. Following this QC check, the remaining PRTs within the fanaspirated PRT at all towers averaged to $0.08^{\circ} \mathrm{C}$. Once these automated QC checks were completed, a manual quality check was applied, which consisted of comparing aspirated and unaspirated temperature measurements at a tower by plotting and inspecting the time series. This analysis identified a period between 6 June and 8 August 2013 where unaspirated PRT measurements from tower $\mathrm{C}$ failed this check and were set to missing. Finally, temperature measurements from all towers (separately for aspirated and nonaspirated temperature instruments) were set to missing if any observation from another tower was missing or failed these QC checks. This last step ensured that aggregated (i.e., mean difference) comparisons between the towers were performed over the same time period and atmospheric condition.

\section{b. USCRN station encroachment}

The encroached USCRN station at Kingston (Plains Road Site), was one of a paired set of USCRN stations that provided a duplicate or reference station (within $1.4 \mathrm{~km}$ ) in this study from which to compare temperature observations and detect changes caused by encroachment. While monthly average maximum and minimum air temperatures were used for comparison when all daily data in the month were available, for months with missing days, only the days that both stations had in common were included in the monthly averages to mitigate biases in the comparison due to missing data. For each month of the year, the average difference between the stations for the period 2006-12 was calculated to create a reference seasonal cycle of station differences. These reference station differences were then subtracted from the individual monthly differences to create difference anomalies. Temperature anomalies were then evaluated before (January 2006December 2012) and after (June 2013-May 2018) encroachment. Any seasonal bias has been avoided by insuring that all 12 months are equally represented in each period.

\section{Results}

\section{a. Field experiment: Urban bias factors}

Observational differences between the closest (tower A) and farthest (tower D) locations relative to the built environment allowed us to evaluate and isolate environmental factors that impact the urban signal in this field experiment. Overall, tower A was warmer than tower D by $0.31^{\circ}$ and $0.23^{\circ} \mathrm{C}$ for aspirated and unaspirated PRTs, 
TABLE 1. Tower A minus tower D mean temperature differences $\left({ }^{\circ} \mathrm{C}\right)$ observed during the day (sunrise to sunset to the nearest hour) and night (sunset to sunrise to the nearest hour) by sensor type.

\begin{tabular}{lccc}
\hline \hline Sensor type & All & Day & Night \\
\hline Aspirated & 0.31 & 0.16 & 0.47 \\
Unaspirated & 0.23 & 0.05 & 0.40 \\
\hline
\end{tabular}

respectively. The mean differences had sizable standard deviations of $0.44^{\circ} \mathrm{C}$ for both PRT types, which suggest that the urban signal was quite variable (Table 1 ). The impact of the artificial heat source on temperature measurements was larger during the evening than day (Table 1). Mean aspirated PRT differences for day and night were $0.16^{\circ}$ and $0.47^{\circ} \mathrm{C}$, respectively. For the unaspirated PRTs, daytime and nighttime temperature biases were slightly smaller at $0.05^{\circ}$ and $0.40^{\circ} \mathrm{C}$, respectively. While the aspirated sensor had slightly larger biases, the gap between daytime and nighttime differences (nighttime minus daytime biases) were similar between aspirated $\left(0.31^{\circ} \mathrm{C}\right)$ and unaspirated $\left(0.35^{\circ} \mathrm{C}\right)$ instruments. In addition, an evaluation of daytime mean absolute differences (MAD) between tower A and tower $\mathrm{D}$ revealed that both aspirated and unaspirated sensors had the same mean absolute difference of $0.19^{\circ} \mathrm{C}$. This suggests that the small mean difference for the unaspirated sensors at tower $\mathrm{A}$ and tower D was not the result of similar temperature observations. In fact, histograms of tower A and tower D temperature differences showed that the unaspirated sensors had a near symmetric distribution about zero compared to a positively skewed (warmer than tower D) distribution of aspirated temperature differences.

Examining the average air temperature differences from tower $\mathrm{A}$ to tower $\mathrm{D}$ for the individual hours of the diurnal cycle provided additional insight. For aspirated PRTs, the difference between tower A and tower D reached a minimum of zero near midday $\left(0.04^{\circ} \mathrm{C}\right)$ and then increased in the afternoon, reaching a maximum of $0.60^{\circ} \mathrm{C}$ shortly after sunset (Fig. 2). Air temperature differences from tower A to tower D gradually diminished overnight and into the morning as the built surfaces cooled (Fig. 2). This diurnal pattern suggests that mean daytime biases for both aspirated and unaspirated sensors were driven by the few early morning and late afternoon hours when the urban and grassy areas experienced differential warming and cooling rates, respectively. This means that both sensors experienced a similar diurnal cycle of temperature differences, but the unaspirated-PRT had a persistent offset that was $0.1^{\circ} \mathrm{C}$ cooler than the average aspirated difference. That said, it should be noted here that midday (1100-1300 LST) differences between tower A

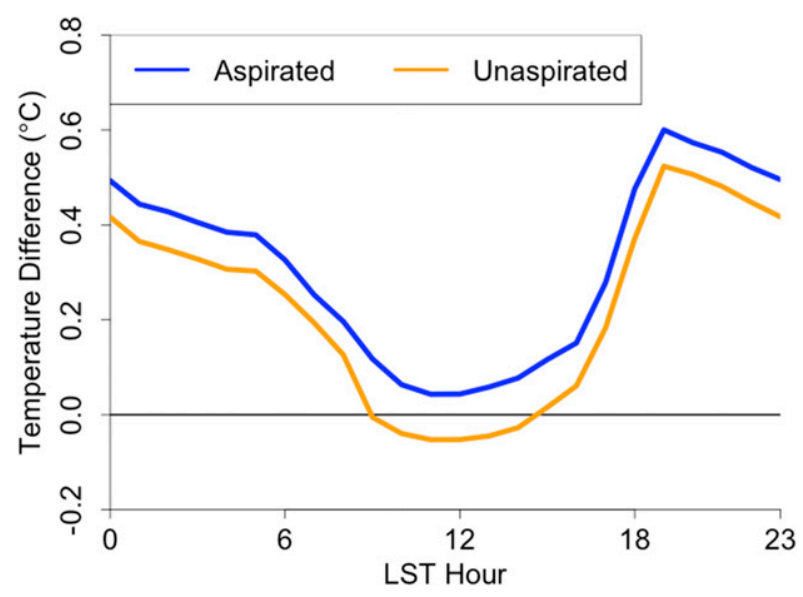

FIG. 2. Hourly averaged temperature differences between tower A and tower D (A - D) for aspirated PRTs (blue) and unaspirated PRTs (orange).

and tower $\mathrm{D}$ for both aspirated $(\sim 0.05)$ and unaspirated $(\sim-0.04)$ were quite small.

To examine this further, temperature biases were broken down by environmental conditions (Fig. 3). In general, temperature differences between tower $\mathrm{A}$ and tower $\mathrm{D}$ were greater during low wind conditions (less than $0.5 \mathrm{~m} \mathrm{~s}^{-1}$; Fig. 3a), which often occurred during the evening. Aspirated temperatures were warmer at tower A compared to tower D for all three wind categories, but unaspirated sensors had a near zero mean difference for wind speeds $>1.5 \mathrm{~m} \mathrm{~s}^{-1}$. This was interesting given that no other environmental variable had a near-zero mean unaspirated temperature difference between tower $\mathrm{A}$ and tower D (Fig. 3), which is why wind conditions have been used in the literature to evaluate the urban bias in climate trends (Parker 2006). Wind from the built environment had a larger impact on air temperature differences between tower A and tower D (Fig. 3b). Essentially, when winds were from the urban area (vectors from southwest to north; Fig. 1) tower A reported warmer temperatures than tower D for both aspirated and unaspirated sensors. Incoming shortwave radiation was also important with more solar radiation resulting in greater temperature contrasts between tower $\mathrm{A}$ and tower $\mathrm{D}$ for both aspirated and unaspirated sensors (Fig. 3c). These results are in line with the literature that shows greater solar radiation enhanced the contrasts between rural and urban environments (Parker 2006; Oke 1982).

Differences in air temperature from tower A to tower D also had a seasonal component. There was a smaller overall difference during winter days, as one would expect from reduced solar heating (shorter days and weaker solar radiation) of the built environment and lowered evapotranspiration rates over the dormant grassy field (Fig. 3d). Spring was generally a time of 
(a)

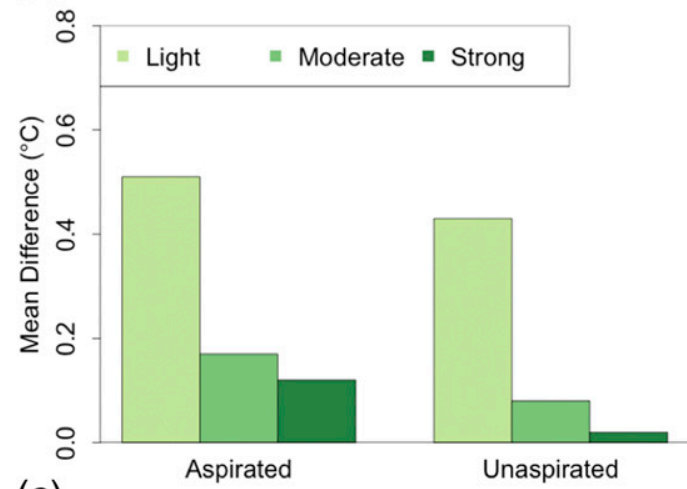

(c)

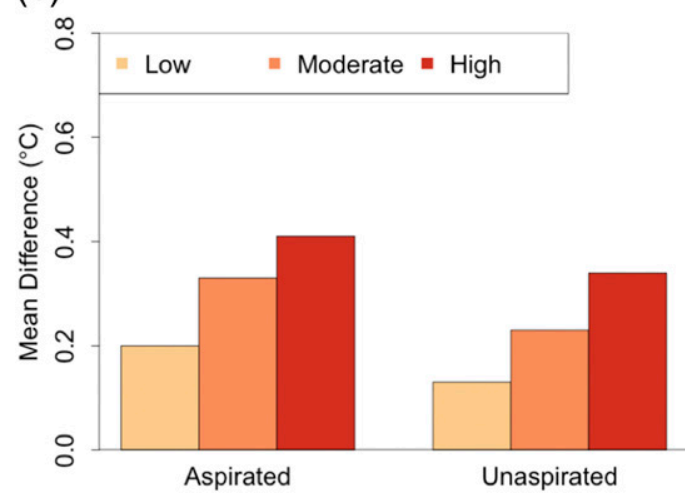

(b)

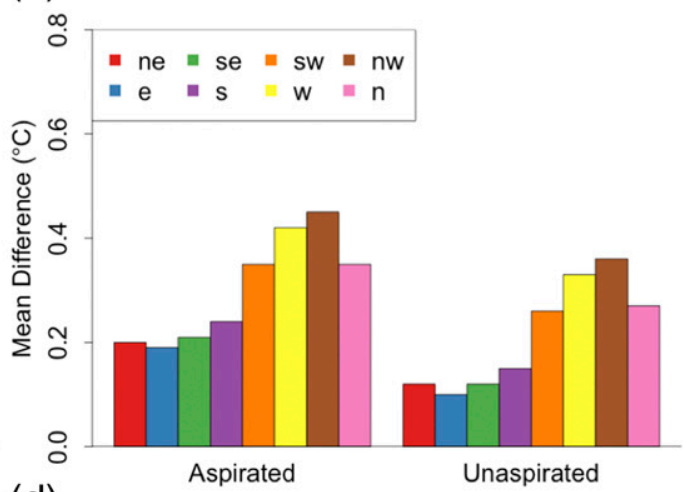

(d)

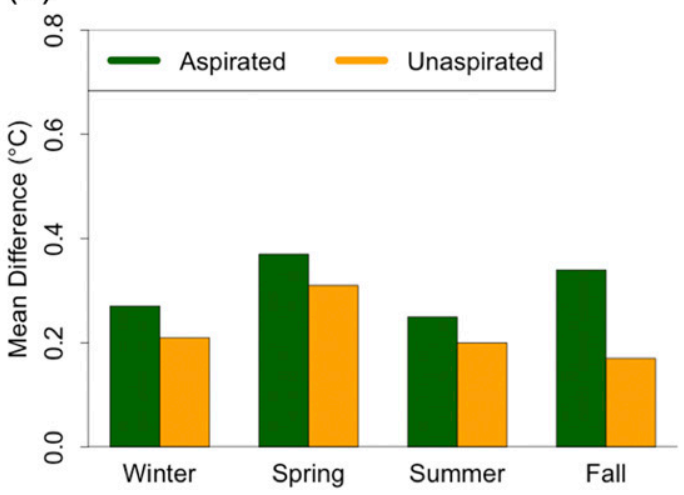

FIG. 3. Tower A mean air temperature differences from tower D by (a) five-minute averaged light (light green; $\left.<0.5 \mathrm{~m} \mathrm{~s}^{-1}\right)$, moderate $\left(0.5-1.5 \mathrm{~m} \mathrm{~s}^{-1}\right)$, and strong (dark green; $\geq 1.5 \mathrm{~m} \mathrm{~s}^{-1}$ ) wind speeds; (b) wind direction in $15^{\circ}$ increments starting from the northeast; (c) past 24-h total solar radiation from low $<10 \mathrm{MJ}$ day $^{-1}$ ), moderate $\left(10-20 \mathrm{MJ} \mathrm{day}^{-1}\right)$, and high ( $\left.\geq 20 \mathrm{MJ} \mathrm{day}^{-1}\right)$; and (d) seasonal by aspirated (green) and nonaspirated (orange) PRTs.

abundant soil moisture in the field (maximizing latent heat differencing) and when combined with longer days (greater solar insolation) resulted in the largest average air temperature difference between tower $\mathrm{A}$ and tower $D$. The summer and fall seasons were wetter than usual (more cloudy days) in 2013 and may partially explain the smaller mean air temperature differences between tower A and tower D compared to spring.

\section{b. Field experiment: Urban bias by distance}

The impact of the built environment on aspirated air temperature observations diminished with distance (Fig. 4). Similar to the previous section, tower D was used as the control to gauge the influence of the built environment. Mean temperature differences decreased by $0.05^{\circ} \mathrm{C}$ from tower $\mathrm{A}(4 \mathrm{~m})$ to tower $\mathrm{B}(30 \mathrm{~m})$, with a sharper decline $\left(0.08^{\circ} \mathrm{C}\right)$ from tower $\mathrm{B}$ to tower $\mathrm{B}^{\prime}$ $(50 \mathrm{~m})$ and $\left(0.09^{\circ} \mathrm{C}\right)$ from tower $\mathrm{B}^{\prime}$ to tower $\mathrm{C}(124 \mathrm{~m})$ (Fig. 4 and 5). Aspirated air temperature differences between tower $\mathrm{C}$ and tower $\mathrm{D}$ were less than $0.1^{\circ} \mathrm{C}$ $\left(0.09^{\circ} \mathrm{C}\right)$, which indicates that the mean urban influence was curtailed considerably before reaching tower $\mathrm{C}$.
As noted earlier, mean temperature differences with respect to tower $\mathrm{D}$ were generally smaller during the day and larger at night (Fig. 5). While the relative magnitudes of mean daytime and nighttime temperature differences

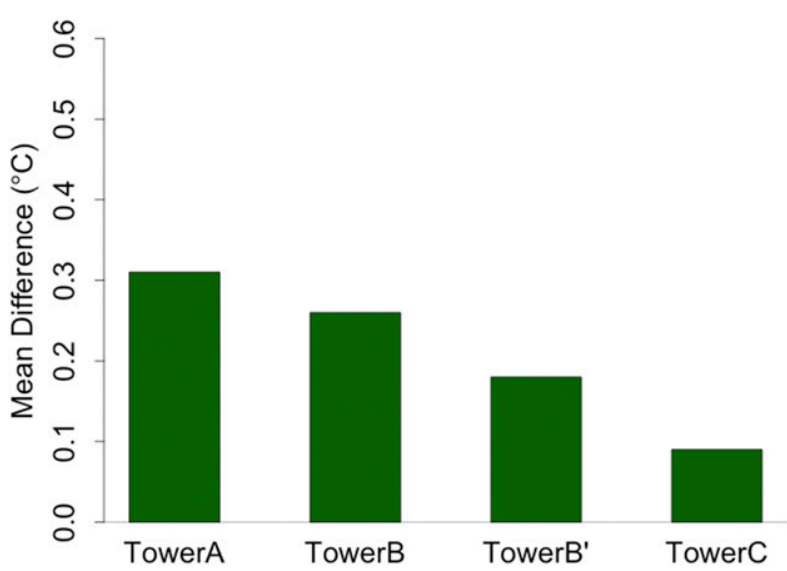

FIG. 4. Tower A (4 m), tower B (30 m), tower B' $(50 \mathrm{~m})$, and tower $\mathrm{C}(124 \mathrm{~m})$ mean air temperature difference computed with respect to tower D $(309 \mathrm{~m})$ for aspirated PRTs. 


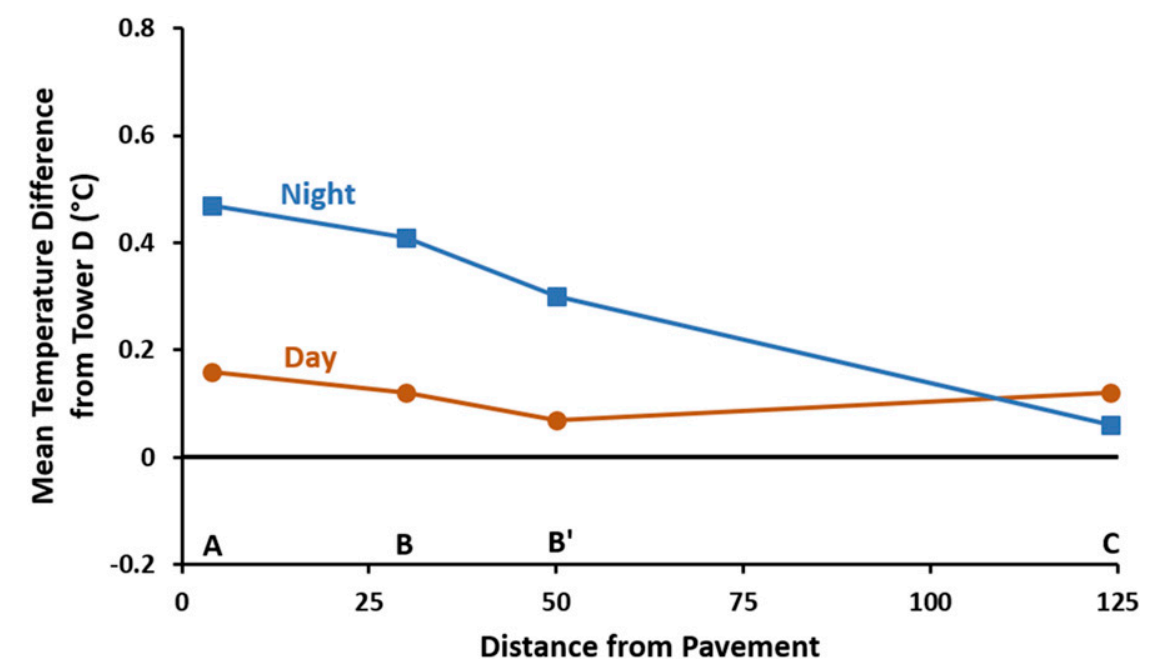

FIG. 5. Mean daytime temperature (orange) and nighttime temperature differences (blue) for aspirated PRTs between each tower and tower D.

both decreased with distance from the urban area, the urban signal during day was already undetectable at tower $\mathrm{B}^{\prime}\left(0.07^{\circ} \mathrm{C}\right)$ located $50 \mathrm{~m}$ from the urban area. In contrast, there was an obvious nighttime urban signal at tower $\mathrm{B}^{\prime}\left(0.30^{\circ} \mathrm{C}\right)$, which became undiscernible $\left(0.06^{\circ} \mathrm{C}\right)$ at tower $\mathrm{C}$. These results suggest that the daytime urban signal had a shorter distance of influence than the nighttime signal. An hourly diurnal analysis of aspirated temperature differences (Fig. 6) showed how the peak magnitude of the urban signal just after sunset diminished with distance.

Aspirated temperature differences were partitioned by environmental conditions found to enhance the urban signal in the first section. For the 2.85 million $16-\mathrm{s}$ 5 -min moving average observations taken during the 18-month experiment, a mean urban signal was detectable as far out as tower $\mathrm{B}^{\prime}$, which was located $50 \mathrm{~m}$ from the built environment (Fig. 7). Filtering these to approximately 1.39 million observations recorded between sunset and sunrise, the nocturnal mean temperature differences for tower $\mathrm{A}$ and tower B, located 4 and $30 \mathrm{~m}$ away, increased from $0.31^{\circ}$ and $0.26^{\circ}$ to $0.47^{\circ}$ and $0.41^{\circ} \mathrm{C}$, respectively. The nocturnal difference at tower $\mathrm{B}^{\prime}$ increased from $0.18^{\circ}$ to $0.30^{\circ} \mathrm{C}$ with tower $\mathrm{C}$ continuing to display little or no urban influence at this distance. Limiting nocturnal observations to those that were preceded by very sunny 24 -h periods (greater than equal to $20 \mathrm{MJ}$ ) further increased the urban signal (based on 338104 observations) to $0.67^{\circ}, 0.56^{\circ}$, and $0.42^{\circ} \mathrm{C}$ at tower $\mathrm{A}$, tower $\mathrm{B}$, and tower $\mathrm{B}^{\prime}$, respectively. These observations were largely limited to warmer months of the experimental period. Finally, if the observations were restricted to nocturnal times following sunny days, and with light winds from the urban area (from $225^{\circ}$ to $315^{\circ}$ compass direction), the mean urban influence (based on 88774 observations) was quite large even out to tower $\mathrm{B}^{\prime}$, where it rose to $0.55^{\circ} \mathrm{C}$. Under these same conditions tower $\mathrm{A}$ and tower $\mathrm{B}$ showed differences of $0.84^{\circ}$ and $0.73^{\circ} \mathrm{C}$, respectively. However, the nighttime, high solar, urban wind conditions had a near zero mean temperature difference at tower $\mathrm{C}$ with respect to tower $\mathrm{D}$. This suggests that no discernable urban signal was detectable from the fan-aspirated PRT located over $100 \mathrm{~m}$ away from the urban area (Fig. 7).

\section{c. Impact of encroachment at Kingston $1 \mathrm{NW}$}

The impacts of land-use change in the area within $100 \mathrm{~m}$ of the USCRN station at Kingston $1 \mathrm{NW}$ (Plains Road Site) were quite revealing when compared to the station at Kingston $1 \mathrm{~W}$ (Peckham Farm Site). The

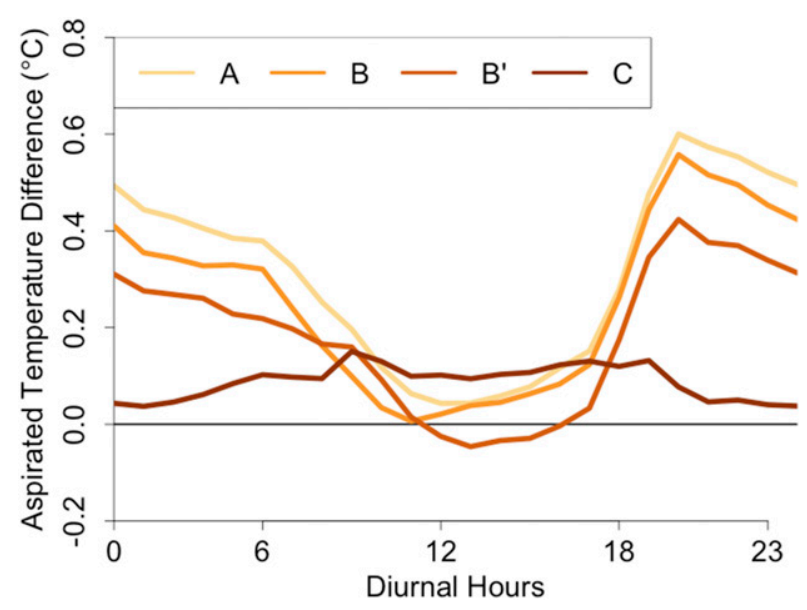

FIG. 6. Diurnal cycle of aspirated air temperature differences between each tower and tower $\mathrm{D}$ for the period of the study. 


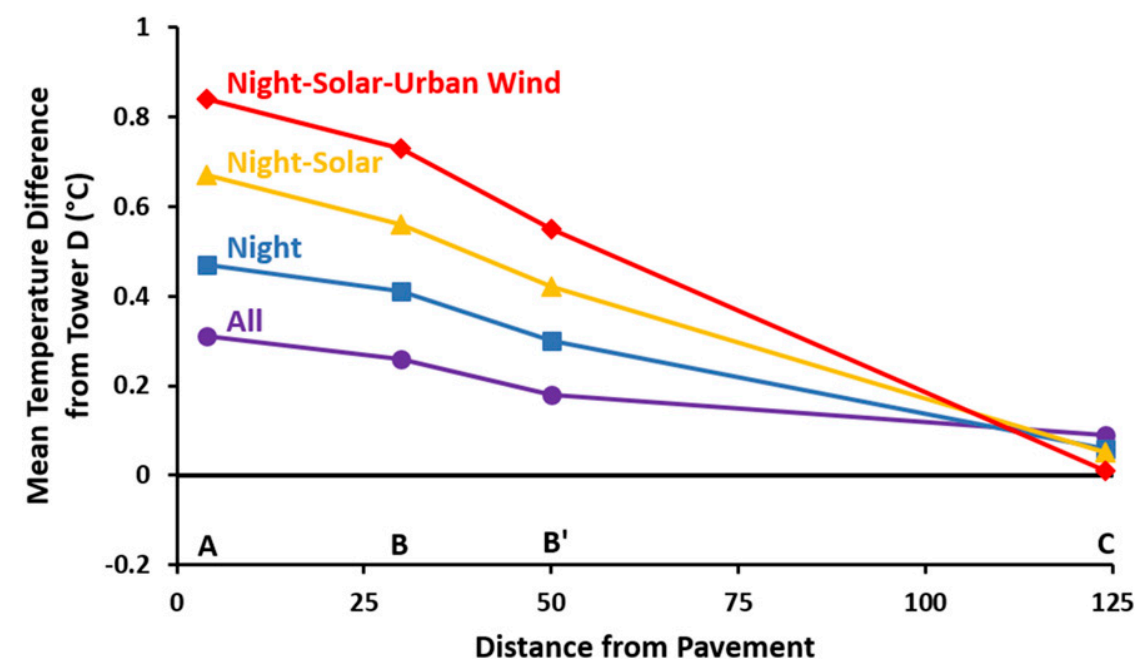

FIG. 7. Mean aspirated temperature differences with respect to tower D for all conditions (black line), nocturnal observations (blue), nocturnal observations on days receiving more than $20 \mathrm{MJ}$ solar radiation (yellow), and nocturnal observations on high solar receipt days with wind from the urban area compass directions $225^{\circ}-315^{\circ}$ (red).

impact of encroachment was quite small for the daily maximum air temperature, $0.09^{\circ} \mathrm{C}$ (Fig. 8a), when compared to changes in the daily minimum air temperature of $0.31^{\circ} \mathrm{C}$ (Fig. 8b). Interestingly, these impacts showed the same type of diurnal differences as between tower $\mathrm{A}$ and tower $\mathrm{D}$ in the field experiment (Table 1). A smaller daytime impact occurred when the atmosphere was well mixed, with a larger nighttime bias when the atmosphere was more stable.

\section{Discussion and conclusions}

The field experiment demonstrated that the impact of an encroaching artificial heating source on nearby air temperature measurements was much larger at night than during the day. The diurnal analyses (Figs. 2 and 6) indicate that differences were quite small between tower A and tower $\mathrm{D}$ for several hours around midday for both aspirated and unaspirated sensors. Nocturnal differences were largest just after sunset and gradually decreased with a sharp drop just after sunrise. These results suggest that the mean daytime bias mainly reflect the hours just after sunrise and before sunset, whereas mean nighttime differences represent the entire nocturnal period. Therefore, the magnitude of mean dayand nighttime encroachment biases would be sensitive to both how day- and nighttime hours are defined, and the temporal resolution of the data.

In the case of daily observations, maximum and minimum temperatures would be sensitive to the time of observation of the 24-h maximum and minimum. Typically, a daily maximum (several hours after solar noon) occurs when the urban signal is quite weak, but the daily minimum (just before sunrise) occurs when the urban signal is still strong (see Fig. 2). This explains why mean midnight-to-midnight maximum temperature biases for aspirated $\left(0.09^{\circ} \mathrm{C}\right)$ and unaspirated $\left(-0.03^{\circ} \mathrm{C}\right)$ sensors between tower $\mathrm{A}$ and tower $\mathrm{D}$ were somewhat smaller than mean daytime subhourly differences of $0.16^{\circ}$ and $0.06^{\circ} \mathrm{C}$, respectively. On the other hand, the mean midnight-to-midnight minimum temperature differences $\left(0.49^{\circ}\right.$ and $\left.0.45^{\circ} \mathrm{C}\right)$ were similar to the average subhourly differences over the nocturnal period $\left(0.47^{\circ}\right.$ and $\left.0.40^{\circ} \mathrm{C}\right)$ for both aspirated and unaspirated sensors. The timing of daily maximum and minimum temperatures in relation to the strength of the urban signal results in an asymmetric temperature response to urban encroachment affecting commonly used measures such as the diurnal temperature range (DTR) and daily temperature averages based on maximum and minimum conditions.

The asymmetric diurnal temperature response to encroachment reduced the midnight-to-midnight DTR of tower A compared to tower D. The reduction in DTR at tower A was slightly greater for the unaspirated sensor $\left(-0.48^{\circ} \mathrm{C}\right)$ than for the aspirated sensor $\left(-0.39^{\circ} \mathrm{C}\right)$. The disparity between the aspirated and unaspirated DTR change was mostly attributed to the unaspirated sensor's cooler daytime temperature bias (Fig. 2) near midday (1100-1300 LST) when daily maximums are generally observed. That said, the changes in DTR between tower $\mathrm{A}$ and tower $\mathrm{D}$ were considered notable given they were of similar magnitude to changes in DTR caused by cloud cover (Xia 2013), precipitation, changes in surface energy 

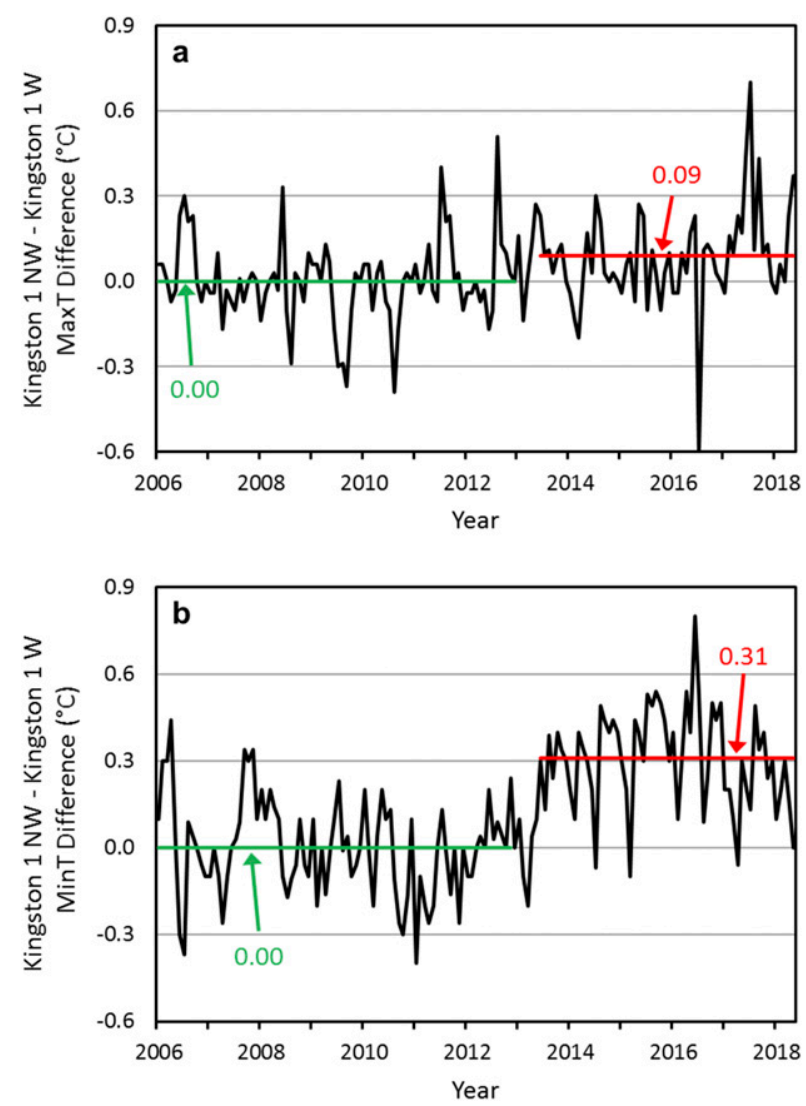

FIG. 8. The monthly mean air temperature difference anomalies between Kingston $1 \mathrm{NW}$ and Kingston $1 \mathrm{~W}$ USCRN stations: (a) daily maximum temperature (MaxT) and (b) daily minimum temperature (MinT). The green lines indicate the average monthly differences from January 2006 through December 2012; the red lines indicate the average monthly differences from June 2013 through May 2018 after the built environment was installed in 2013.

budgets (Dai et al. 1999, 1997), and other nonlocalized human influences such as aerosols (Guo et al. 2017), which is rather significant since we are only considering small-scale urban encroachment. These results were also sensitive to the time of observation of daily maximum and minimum temperatures. The midnight-to-midnight reduction in DTR at tower A was slightly reduced when using other common morning [0700 local time (LT)] and afternoon (1700 LT) observation times in the Global Historical Climatology Network (Table 2). However, these changes were less than $0.07^{\circ}$ and $0.08^{\circ} \mathrm{C}$ for aspirated and unaspirated sensors, respectively.

There were slight differences between aspirated and unaspirated PRT biases at tower A. This was more notable during midday when unaspirated PRT measurements at tower A were on average cooler than the unaspirated sensors at tower D. However, aspirated and unaspirated sensors had similar measures of mean absolute deviation $\left(0.26^{\circ} \mathrm{C}\right)$. Histograms of the unaspirated and aspirated
TABLE 2. Mean diurnal temperature range change between tower A and tower D (A - D) for aspirated and unaspirated sensors for midnight (0000 LT), morning (0700 LT), and afternoon (1700 LT) observers.

\begin{tabular}{lcc}
\hline \hline \multicolumn{1}{c}{$\begin{array}{c}\text { Observation } \\
\text { time }\end{array}$} & $\begin{array}{c}\text { Aspirated DTR } \\
\text { change }\left({ }^{\circ} \mathrm{C}\right)\end{array}$ & $\begin{array}{c}\text { Unaspirated DTR } \\
\text { change }\left({ }^{\circ} \mathrm{C}\right)\end{array}$ \\
\hline Midnight (0000 LT) & -0.39 & -0.48 \\
Morning (0700 LT) & -0.34 & -0.42 \\
Afternoon (1700 LT) & -0.32 & -0.40 \\
\hline
\end{tabular}

sensor differences (not shown here) showed that the unaspirated sensor had a slightly broader distribution (higher standard deviation of $0.36^{\circ}$ compared to $0.33^{\circ} \mathrm{C}$ ) that was shifted toward zero compared to the aspirated sensor. Some of this disparity could be attributed to subtle wind differences across the field causing slightly different levels of natural aspiration between tower A and tower D. As a result, the aspirated PRTs are thought to provide a better assessment of the impacts of encroachment on air temperature than the unaspirated PRTs. In addition, this also suggests that the detection of an urban signal may be more forth coming with aspirated than unaspirated sensors.

The impact of encroachment may also have impacted the well-known relationship between aspirated and unaspirated sensors where aspirated sensors observe warmer minimums and cooler maximums compared to unaspirated sensors (Leeper et al. 2015). DTR differences between aspirated and unaspirated sensors at tower A were $0.09^{\circ} \mathrm{C}$ smaller than the aspirated and unaspirated DTR differences at tower D (Fig. 9). These results suggest that the aspirated sensors' warmer daytime bias due to encroachment at tower A may have offset any expected cooling due to fan aspiration. However, it is not clear how well these results extend beyond this field experiment given the sensitivity of unaspirated sensors to microscale wind conditions as previously noted, but this finding certainly deserves further exploration.

The reach of the urban bias differed between daytime and nighttime conditions. It was largest during evenings following sunny days, when light winds were from the direction of the built environment. The mean urban bias for these conditions quickly dropped from $0.84^{\circ} \mathrm{C}$ at tower $\mathrm{A}(4 \mathrm{~m})$ to $0.55^{\circ}$ and $0.01^{\circ} \mathrm{C}$ at towers $\mathrm{B}^{\prime}$ and $\mathrm{C}$ located 50 and $124 \mathrm{~m}$ from the small-scale built environment. Despite a mean urban signal near $0.9^{\circ} \mathrm{C}$ at tower $\mathrm{A}$, the mean urban biases were not statistically significant given the magnitude of the towers standard deviations; $0.44^{\circ}, 0.40^{\circ}, 0.37^{\circ}$, and $0.31^{\circ} \mathrm{C}$ for towers $\mathrm{A}, \mathrm{B}$, $\mathrm{B}^{\prime}$, and $\mathrm{C}$, respectively. To evaluate this further, an analysis of the percent of observations exceeding two standard deviations of the respective towers' differences from tower $\mathrm{D}$ for each of the conditions (all, night, nightsolar, and night-solar-urban winds) provide a measure of 


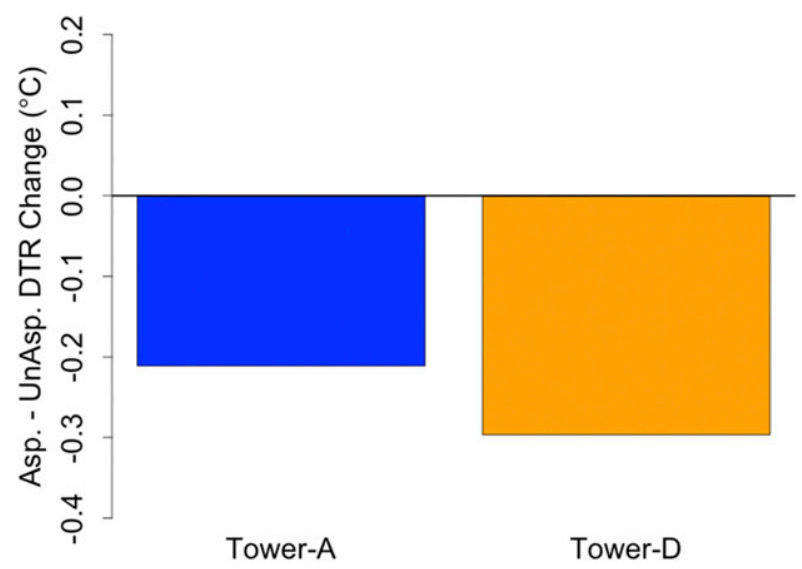

FIG. 9. Mean aspirated minus unaspirated air diurnal temperature range differences for tower A (blue) and tower D (orange).

the frequency of extreme differences (Fig. 10). At tower A, $44.4 \%$ or nearly half of the night-solar-urban wind observations met or exceeded the two standard deviation level. The percentage dropped to $39.8 \%$ and $30.1 \%$ at towers $\mathrm{B}$ and $\mathrm{B}^{\prime}$ before plummeting to $5.6 \%$ at tower $\mathrm{C}$. These results suggest that while mean differences with respect to tower D may not have been statistically significant at some towers, the frequency of extreme temperature differences were certainly more likely for towers located near the built environment.

In summary, the field experiment supports the recommendation that air temperature observations sites should be located over $100 \mathrm{~m}$ from artificial heat sources, which is in line with WMO recommendations (Leroy 1998; WMO 2014). The urban signal was greatest for evenings following sunny days with light winds from the urban area, which was strongly detectable as far away as $50 \mathrm{~m}$. In addition, the reach of the urban signal differed between daytime and nighttime conditions and to some extent with aspiration type. The subtle differences between aspirated and unaspirated sensors in the magnitude of the urbanization signal suggest that some consideration of sensing technology is necessary in encroachment signal detection and other UHI studies. This is particularly true for unaspirated temperature measurements, which can have additional sensitivities to localized wind conditions even at the field scale that can obfuscate these types of studies.

Finally, the reported reduction in DTR due to encroachment-related warming of minimum temperatures is interesting given that climatologically, over the latter half of the twentieth century, DTR has decreased because of warming minimum temperatures, especially from the 1960 s to 1980s (Liu et al. 2018; Thorne et al. 2016a,b). Because this is a global signal, seen at rural climate stations as well as urban and

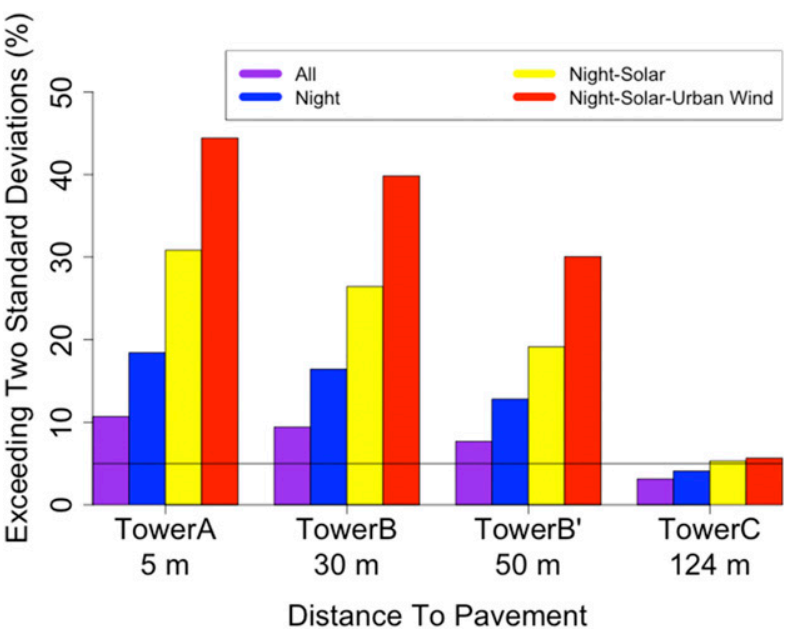

FIG. 10. Percentage of observations for all (purple), night (blue), nights preceding sunny days (yellow), and nights preceding sunny days with light winds from the urban area that equal or exceed two standard deviations of the respective tower's differences from tower D (red).

suburban (Thorne et al. 2016a; Vose et al. 2005; Karl et al. 1993), the decrease in DTR has been attributed mainly to nonurban processes [i.e., changes in cloud cover (Xia 2013), precipitation and energy budgets (Dai et al. 1999, 1997), aerosols (Guo et al. 2017), and others (Kukla and Karl 1993)]. However, even smallscale urban encroachment can result in asymmetric responses between daytime and nighttime air temperatures. As a result, DTR and other temperature studies would stand to benefit from the availability of landcover and instrumentation metadata. Other observation networks should consider USCRN's practice of taking land-cover photos during annual maintenance visits to document changes in station siting. In the absence of such documentation, it is hoped this analysis will provide some insight regarding approaches that can be developed to detect land-cover change, particularly smallscale encroachment, from station temperature records. More study of the interactions of temperature observations with urban encroachment, shielding, and instrumentation type would be beneficial in this endeavor.

Acknowledgments. This work was supported by NOAA through the Cooperative Institute for Climate and Satellites-North Carolina under Cooperative Agreement NA14NES432003. A special thanks to North Carolina State Climate Office and the Atmospheric Turbulent Diffusion Division (ATDD) as well as comments from Matthew Minnie, Michael Kruk, and Ed Dumas for their contributions to this manuscript, as well as recommendations from the two anonymous reviewers. 


\section{REFERENCES}

Arnfield, A. J., 2003: Two decades of urban climate research: A review of turbulence, exchanges of energy and water, and the urban heat island. Int. J. Climatol., 23, 1-26, https://doi.org/ 10.1002/joc.859.

Battisti, D. S., and R. L. Naylor, 2009: Historical warnings of future food security with unprecedented seasonal heat. Science, $\mathbf{3 2 3}$, 240-244, https://doi.org/10.1126/science.1164363.

Bunker, A., J. Wildenhain, A. Vandenbergh, N. Henschke, J. Rocklov, S. Hajat, and R. Sauerborn, 2016: Effects of air temperature on climate-sensitive mortality and morbidity outcomes in the elderly; a systematic review and meta-analysis of epidemiological evidence. EBioMedicine, 6, 258-268, https://doi.org/10.1016/j.ebiom.2016.02.034.

Dai, A., A. Del Genio, and I. Y. Fung, 1997: Clouds, precipitation, and temperature range. Nature, 386, 665-666, https://doi.org/ $10.1038 / 386665 b 0$.

— moisture, precipitation, and water vapor on diurnal temperature range. J. Climate, 12, 2451-2473, https://doi.org/10.1175/ 1520-0442(1999)012<2451:EOCSMP>2.0.CO;2.

Diamond, J. H., and Coauthors, 2013: U.S. Climate Reference Network after one decade of operations. Bull. Amer. Meteor. Soc., 94, 485-498, https://doi.org/10.1175/BAMS-D12-00170.1.

Gallo, K. P., T. W. Owen, D. R. Easterling, and P. F. Jamason, 1999: Temperature trends of the U.S. Historical Climatology Network based on satellite designated land use/land cover. J. Climate, 12, 1344-1348, https://doi.org/10.1175/1520-0442(1999) 012<1344:TTOTUS $>2.0$. CO;2.

Grossman-Clarke, S., J. A. Zehnder, T. Loridan, and C. S. B. Grimmond, 2010: Contribution of land use changes to nearsurface air temperatures during recent summer extreme heat events in the Phoenix metropolitan area. J. Appl. Meteor. Climatol., 49, 1649-1664, https://doi.org/10.1175/ 2010JAMC2362.1.

Guo, J., and Coauthors, 2017: Declining frequency of summertime local-scale precipitation over eastern China from 1970-2010 and its potential link to aerosols. Geophys. Res. Lett., 44, 5700 5708, https://doi.org/10.1002/2017GL073533.

Hausfather, Z., M. J. Menne, C. N. Williams Jr., T. Masters, R. Broberg, and D. Jones, 2013: Quantifying the effect of urbanization on U.S. Historical Climatology Network temperature records. J. Geophys. Res. Atmos., 118, 481-494, https:// doi.org/10.1029/2012JD018509.

Karl, T. R., and Coauthors, 1993: A new perspective on recent global warming: Asymmetric trends of daily maximum and minimum temperature. Bull. Amer. Meteor. Soc., 74, 1007-1023, https://doi.org/10.1175/1520-0477(1993)074<1007: ANPORG $>2.0 . \mathrm{CO} ; 2$.

Kukla, G., and T. R. Karl, 1993: Nighttime warming and the greenhouse effect. Environ. Sci. Technol., 27, 1468-1474, https://doi.org/10.1021/es00045a001.

Kumamoto, M., M. Otsuka, T. Sakai, T. Hamagami, H. Kawamura, T. Aoshima, and F. Fujibe, 2013: Field experiment on the effects of a nearby asphalt road on temperature measurement. SOLA, 9, 56-59, https://doi.org/10.2151/ sola.2013-013.

Leeper, R. D., J. Rennie, and M. A. Palecki, 2015: Observational perspectives from U.S. Climate Reference Network (USCRN) and Cooperative Observer Program (COOP) Network: Temperature and precipitation comparison.
J. Atmos. Oceanic Technol., 32, 703-721, https://doi.org/ 10.1175/JTECH-D-14-00172.1.

Leroy, M., 1998: Meteorological measurement representativeness, nearby obstacles influence. WMO Tech. Conf. on Meteorological and Environmental Instruments and Methods of $\mathrm{Ob}$ servation (TECO-1998), Instruments and Observing Methods Rep. 70, WMO/TD 877, Casablanca, Morocco, WMO, 11.5, 51-54.

Liu, L., J. Guo, W. Chen, R. Wu, L. Wang, H. Gong, W. Xue, and J. Li, 2018: Large-scale pattern of the diurnal temperature range changes over East Asia and Australia in boreal winter: A perspective of atmospheric circulation. J. Climate, 31, 27152728, https://doi.org/10.1175/JCLI-D-17-0608.1.

Lobell, D. B., 2007: Changes in diurnal temperature range and national cereal yields. Agric. For. Meteor., 145, 229-238, https://doi.org/10.1016/j.agrformet.2007.05.002.

Mahmood, R., and Coauthors, 2014: Land cover changes and their biogeophysical effects on climate. Int. J. Climatol., 34, 929953, https://doi.org/10.1002/joc.3736.

Menne, M. J., and C. N. Williams Jr., 2009: Homogenization of temperature series via pairwise comparisons. J. Climate, 22, 1700-1717, https://doi.org/10.1175/2008JCLI2263.1.

—_ — , and R. S. Vose, 2009: The United States Historical Climatology Network monthly temperature data-Version 2. Bull. Amer. Meteor. Soc., 90, 993-1007, https://doi.org/ 10.1175/2008BAMS2613.1.

- — , and M. A. Palecki, 2010: On the reliability of the U.S. surface temperature record. J. Geophys. Res., 115, D11108, https://doi.org/10.1029/2009JD013094.

NOAA, 2002: Climate reference network (CRN) site information handbook. Rep. NOAA-CRN/OSD-2002-0002R0UD0, 29 pp., https://www1.ncdc.noaa.gov/pub/data/uscrn/documentation/ program/X030FullDocumentD0.pdf.

Oke, R. T., 1982: The energetic basis of the urban heat island. Quart. J. Roy. Meteor. Soc., 108, 1-24, https://doi.org/10.1002/ qj.49710845502.

Paaijmans, K. P., S. Blanford, A. S. Bell, J. I. Blanford, A. F. Read, and M. B. Thomas, 2010: Influence of climate on malaria transmission depends on daily temperature variation. Proc. Natl. Acad. Sci. USA, 107, 15 135-15 139, https:// doi.org/10.1073/pnas.1006422107.

Parker, D. E., 2006: A demonstration that large-scale warming is not urban. J. Climate, 19, 2882-2895, https://doi.org/10.1175/ JCLI3730.1.

Peterson, T., 2003: Assessment of urban versus rural in situ surface temperatures in the contiguous United States: No difference found. J. Climate, 16, 2941-2959, https://doi.org/ 10.1175/1520-0442(2003)016<2941:AOUVRI > 2.0.CO;2.

Shem, W., and J. M. Shepherd, 2009: On the impact of urbanization on summertime thunderstorms in Atlanta: Two numerical model case studies. Atmos. Res., 92, 172-189, https://doi.org/ 10.1016/j.atmosres.2008.09.013.

Streutker, R. D., 2003: Satellite-measured growth of the urban heat island of Houston, Texas. Remote Sens. Environ., 85, 282-289, https://doi.org/10.1016/S0034-4257(03)00007-5.

Thorne, P. W., and Coauthors, 2016a: Reassessing changes in diurnal temperature range: A new data set and characterization of data biases. J. Geophys. Res. Atmos., 121, 5115-5137, https://doi.org/10.1002/2015JD024583.

, and Coauthors, 2016b: Reassessing changes in diurnal temperature range: Intercomparison and evaluation of existing global data set estimates. J. Geophys. Res. Atmos., 121, 51385158, https://doi.org/10.1002/2015JD024584. 
Quayle, R. G., D. R. Easterline, T. R. Karl, and P. Y. Hughes, 1991: Effects of recent thermometer changes in the Cooperative Station Network. Bull. Amer. Meteor. Soc., 72, 1718-1724, https:// doi.org/10.1175/1520-0477(1991)072<1718:EORTCI >2.0.CO;2.

Vose, R. S., D. R. Easterling, and B. Gleason, 2005: Maximum and minimum temperature trends for the globe: An update through 2004. Geophys. Res. Lett., 32, L23822, https://doi.org/ 10.1029/2005GL024379.

Williams, C. N., Jr., M. J. Menne, and P. W. Thorne, 2012: Benchmarking the performance of pairwise homogenization of surface temperatures in the United States. J. Geophys. Res., 117, D05116, https://doi.org/10.1029/2011JD016761.
WMO, 2014: Siting classifications for surface observing stations on land. Annex 1B, Guide to Meteorological Instruments and Methods of Observation, WMO 8, 31-42, http://www.wmo.int/ pages/prog/www/IMOP/SitingClassif/SitingClassif.html.

Xia, X., 2013: Variability and trend of diurnal temperature range in China and their relationship to total cloud cover and sunshine duration. Ann. Geophys., 31, 795-804, https://doi.org/10.5194/ angeo-31-795-2013.

Yi, C., and Coauthors, 2010: Climate control of terrestrial carbon exchange across biomes and continents. Environ. Res. Lett., 5, 034007, https://doi.org/10.1088/1748-9326/5/3/ 034007. 